(c) Journal of Applied Mathematics \& Decision Sciences, 1(1), 27-43 (1997)

Reprints Available directly from the Editor. Printed in New Zealand.

\title{
Dynamical Systems Modelling of the Interactions of Animal Stocking Density and Soil Fertility in Grazed Pasture
}

\author{
I D WICKHAM AND G C WAKE \\ Department of Mathematics, University of Auckland, Auckland, New Zealand \\ S J R WOODWARD AND B S THORROLD \\ AgResearch, Whatawhata Research Center, Private Bag 3089, Hamilton, New Zealand
}

\begin{abstract}
To examine the long-term effects of fertiliser application on pasture growth under grazing, a mathematical representation of the pasture ecosystem is created and analysed mathematically. From this the nutrient application level needed to maintain a given stocking rate can be determined, along with its profitability. Feasible stocking levels and fertiliser application rates are investigated and the optimal combination found, along with the sensitivity of this combination. It is shown that profitability is relatively insensitive to fertiliser level compared with stocking rate.
\end{abstract}

Keywords: Optimal strategy, agricultural systems.

\section{Introduction}

A grazed pasture ecosystem consists of pasture, climate, soil and animals interacting through many different processes (Snaydon 1981). It is necessary to simplify this system in order to examine the dynamics between soil nutrient and pasture mass levels under grazing.

Previous models of nutrient cycling in soils have focused on the soil-plant response to fertiliser addition (e.g., Cornforth \& Sinclair, 1984 ; Metherell et. al., 1995) and have made over-simplified assumptions regarding the way that the plant-animal system responds to fertiliser input. Given the feedback between pasture mass and pasture growth rate, the seasonal nature of pasture growth and animal demand, and the seasonal pattern of pasture growth response to soil fertility, a more dynamic representation of pasture and animal production response to fertiliser use would be expected to better define optimum production levels.

Soil fertility level and pasture growth rate are controlled by a number of factors. Some of these are controlled by the farmer (e.g., fertiliser input, stocking rate) while others are uncontrollable (e.g., rain fall) and may vary seasonally (e.g., temperature). In this paper we will concentrate on two factors under farmer control, namely fertiliser rate and stocking rate. We will test the qualitative behaviour of the model as assessed by its predictions of long term system behaviour under con- 
stant fertiliser input and sensitivity to control parameters.

Several assumptions are made. For the purposes of this model, phosphorus $(\mathrm{P})$ is used as a typical fertiliser, and it is assumed that other nutrients are freely available. The grazing animals are assumed to be sheep (ewes). These choices will principally affect the parameter values in the model, since the biological processes are qualitatively similar for other nutrients and stock classes. The model may be used to model other fertiliser nutrients or livestock classes by altering the appropriate parameter values.

The dynamical systems approach attempts to assemble a model by constructing and linking mechanistic sub-models of the various important interactions at work in the system. These sub-models are based on data from controlled field experiments that isolate the relationships. Having constructed the model, it is analysed and verified using dynamical systems techniques. As necessary those relationships which need to be examined more closely are identified, in order to stimulate further field experiments in these areas.

\section{The Model}

This model describes only the dynamics of pasture biomass $\left(Y \mathrm{kgDM} \mathrm{ha}^{-1}\right)$ and soil fertility $\left(F \mathrm{kgP} \mathrm{ha}{ }^{-1}\right)$ as they interact over several years with constant annual fertiliser application and stocking levels.

\subsection{Pasture Dynamics}

The daily net rate of pasture accumulation is given by the amount that the plants grow less the amount that is removed by grazing and senescence. Each of the process sub-models will be documented in detail.

\subsubsection{Net Plant Growth}

A response function has been formulated for net daily pasture accumulation (growth less senescence, neglecting the time delay involved in the latter) which is dependent only on photosynthesising leaf area and fertiliser availability but not on seasonality. This assumes that seasonal effects are of secondary importance and annual average effects dominate. Thus plant growth is dependent on soil nutrient and pasture biomass independently of one another. Mitscherlich equations are often used to describe yield-soil fertility relationships (Metherell et. al. 1995, Woodward 1996, in press a, in press b). We have used a Michaelis-Menten equation for ease of mathematical analysis, in the knowledge that the qualitative form is the same as the Mitscherlich, which if used gives no significant changes to the qualitative 
outcomes when evaluated numerically. The response to pasture mass is modelled as a logistic function. This gives:

$$
\text { net growth rate }=\frac{a F}{d+F}\left(Y-\frac{Y^{2}}{K}\right) \quad \mathrm{kgDM} \mathrm{ha}^{-1} \mathrm{day}^{-1}
$$

where the variables and parameters, along with their approximate values, are described in Table 1.

Table 1. State variables, parameters and their estimated values and units.

\begin{tabular}{|c|c|c|c|}
\hline & Estimate & Units & Description \\
\hline$Y$ & & $\mathrm{kgDM} \mathrm{ha}^{-1}$ & pasture biomass \\
\hline$F$ & & $\mathrm{kgP} \mathrm{ha}^{-1}$ & plant available soil $\mathrm{P}$ mass \\
\hline$a$ & 0.05 & $\mathrm{day}^{-1}$ & relative growth rate parameter \\
\hline$d$ & 200 & $\mathrm{kgP}_{\mathrm{ha}}-1$ & $\begin{array}{l}\text { soil } P \text { level at which half maximum plant } \\
\text { growth occurs }\end{array}$ \\
\hline$K$ & 4000 & $\mathrm{kgDM} \mathrm{ha}^{-1}$ & maximum pasture mass \\
\hline$n$ & $0-40$ & ewes $\mathrm{ha}^{-1}$ & stocking rate \\
\hline$r$ & 0.00075 & ha ewe $^{-1}$ day $^{-1}$ & individual consumption coefficient \\
\hline$m$ & $0-0.27$ & $\mathrm{kgP} \mathrm{ha}^{-1} \mathrm{day}^{-1}$ & fertiliser application rate $\left(0-100{\mathrm{kgP} \mathrm{yr}^{-1}}^{-1}\right.$ \\
\hline$s$ & 0.00011 & day $^{-1}$ & soil loss coefficient \\
\hline$\beta$ & 0.3 & & fraction of nutrient lost from the soil $\mathrm{P}$ pool \\
\hline$\rho$ & 0.0055 & 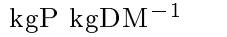 & maximum concentration of nutrient in herbage \\
\hline$c$ & 200 & $\mathrm{kgP}_{\mathrm{ha}}-1$ & $\begin{array}{l}\text { soil } \mathrm{P} \text { level at which half maximum herbage } \mathrm{P} \\
\text { concentration occurs }\end{array}$ \\
\hline
\end{tabular}

If seasonal patterns of growth and response are to be incorporated, $a, d$ and $K$ may be made time dependent with a period of 365 days. However, significant progress can be made by taking the annual average values for each of these parameters, as our initial interest is in long-term effects rather than intra-annual dynamics. A seasonal formulation would require a numerical analysis.

\subsubsection{Grazing}

A linear assumption gives a good approximation for intake rate where pasture mass is low (500 - $1800 \mathrm{kgDM} \mathrm{ha}{ }^{-1}$ ) (Bircham 1981). While a Michaelis-Menten function may be more appropriate (Woodward, in press a), fertilised pastures will tend to carry high stocking levels so the pasture mass remains low. Thus we expect nonlinear effects in removal of pasture mass to be minimal, and this turns out to be the case for the values of $m$ (application rate) and $n$ (stocking rate) considered in the threshold analysis. Therefore we can write:

$$
\text { intake rate }=n r Y \quad \mathrm{kgDM} \mathrm{ha}^{-1} \mathrm{day}^{-1} .
$$


Similarly as in equation (1) we assume that $r$ and $n$ are constant over time. Seasonal changes in management and animal physiological state will cause $r$ and $n$ to vary in practice, but the consideration of seasonality is a second step in the analysis of the model.

Together with the net growth response (equation (1)) this gives a differential equation for the rate of change of pasture mass, $Y$ :

$$
\frac{d Y}{d t}=\frac{a F}{d+F}\left(Y-\frac{Y^{2}}{K}\right)-n r Y
$$

\subsection{Fertility Dynamics}

The accumulation rate of plant available nutrient in the soil is the quantity that the farmer applies less the amount that is lost through net transformation to unavailable forms, erosion or leaching, less the amount removed from the system by the animals. For a typical annual fertiliser application level, the proportion of nutrient in the pasture and animal is of the order of $1-2 \%$ of the total nutrient in the system (Nguyen and Goh 1992), so the nutrient cycle through plant, animal and back to soil is not handled explicitly, but through a net loss process as described below (Metherell et. al., 1995).

\subsubsection{Fertiliser Application}

We assume that fertiliser application may be averaged over the year, so that $m$ is the average daily application level. If more accurate predictions were required it would be necessary to introduce a function $m(t)$ that took account of the fact that fertiliser is applied periodically (e.g. annually), and does not instantly enter the soil.

\subsubsection{Soil Related Losses}

Losses of $\mathrm{P}$ fertiliser can occur within the soil due to leaching, erosion or by transformation into non-available forms of P. In moderately fertilised grassland systems the major part of this loss appears to be due to transformation within the soil (Metherell et. al., 1995). Leaching of $\mathrm{P}$ and $\mathrm{P}$ losses in soil erosion are generally small (Lambert et. al., 1985). Following Metherell et. al., (1995) we assume the loss of soil $\mathrm{P}$ is a constant proportion (s) of the current soil $\mathrm{P}$ level:

$$
\text { soil-loss rate }=s F \quad \mathrm{kgP} \mathrm{ha}^{-1} \mathrm{day}^{-1} \text {. }
$$




\subsubsection{Animal Uptake Through Grazing}

The $\mathrm{P}$ in pasture mass is consumed by the ewe and either converted to meat, wool and bone or returned to the pasture in dung. Conversion to meat, wool or bone is a loss from the soil $\mathrm{P}$ pool. A proportion of the dung is not returned to the pasture, but is transferred to stock camps and other non-productive areas. In this model we combine these two animal related loss processes and assume that a constant proportion $(\beta)$ of $\mathrm{P}$ intake is lost from the soil. Research has shown that this proportion varies for stock type and farm system (Metherell et. al., 1995), but in our qualitative assessment of model behaviour we can assume a constant.

The $\mathrm{P}$ concentration $\left(\mathrm{kgP} \mathrm{kg}^{-1} \mathrm{DM}\right)$ of pasture is approximated by a MichaelisMenten function. We already have the amount of pasture consumed by the animals (equation 2) so that we can determine the animal related loss rate as:

$$
\begin{aligned}
\text { animal-loss rate } & =\text { fraction lost } \times \mathrm{P} \text { in pasture } \times \text { pasture intake } \\
& =\frac{\beta \rho F}{c+F} n r Y
\end{aligned}
$$

where the variables and parameters, along with their approximate values are given in Table 1. Together with the soil loss and application terms this gives a differential equation for the net accumulation rate of fertiliser nutrient in the soil:

$$
\frac{d F}{d t}=m-s F-\frac{\beta \rho F}{c+F} n r Y
$$

\subsection{Dynamical Systems Model}

The dynamical systems model consists of these two differential equations (equations (3) and (7)). Changes in one variable affect the rate of change of the other, giving a coupled system of two equations:

$$
\begin{aligned}
& \frac{d Y}{d t}=\frac{a F}{d+F}\left(Y-\frac{Y^{2}}{K}\right)-n r Y \\
& \frac{d F}{d t}=m-s F-\frac{\beta \rho F}{c+F} n r Y
\end{aligned}
$$

where the variables and parameters are described in Table 1 . These coupled equations capture the essence of the pasture/fertiliser system dynamics in a manner that allows direct analysis and also shows the interaction between the state variables explicitly. 


\section{Analysis and Results}

A fourth-order Runge-Kutta implementation was used to generate solutions of the system from various initial conditions. The qualitative behaviour of the system depends greatly on the value of the parameters, and so stability analysis is required to fully understand the system dynamics and to determine stocking levels which may be supported by various fertiliser regimes, optimal stocking and fertiliser application rate.

$m$ (fertiliser application rate) and $n$ (stocking rate) are treated as "control" parameters and we examine the behaviour of the system when these are varied. Mathematical solutions with negative nutrient or pasture biomass are ignored. For ease of understanding and interpretation in the biological context, we have analysed the equations in dimensional form. More complex extensions of this system may require us to nondimensionalise the equations, thus reducing the number of parameters (which in the present case would reduce the number of parameters from ten to five).

\subsection{Stability and Steady States}

The long-term tendencies of the system are important to the farmer, as they show the sustainable equilibrium states of the system. These steady state solutions, or equilibrium points, are the solutions to the differential equations that do not change with time, and are found by equating both differential equations to zero, i.e.:

$$
\begin{aligned}
& \frac{a F}{d+F}\left(Y-\frac{Y^{2}}{K}\right)-n r Y=0, \\
& m-s F-\frac{\beta \rho F}{c+F} n r Y=0 .
\end{aligned}
$$

The steady state solutions are points $(Y, F)$ that satisfy these equations. One such solution occurs at:

$$
\left(0, \frac{m}{s}\right)
$$

This point corresponds to the extinction of the pasture and an equilibrium between fertiliser input and soil $\mathrm{P}$ related losses. This is the theoretical long-term result when stocking rate is too great to be supported on the pasture grown.

Another equilibrium point is found by substituting

$$
Y=K\left(1-\frac{n r(d+F)}{a F}\right)
$$


(rearranging equation (10)) into equation (11) and solving for $F$. The relevant value of $F$ is the solution of a quadratic given by:

$$
F^{*}=\frac{B+\sqrt{B^{2}+4 A C}}{2 A}
$$

where:

$$
\begin{aligned}
& A=a s \\
& B=a(m-c s)+K \beta \rho n r(n r-a) \\
& \text { and } C=K \beta \rho n^{2} r^{2} d+a c m,
\end{aligned}
$$

and the corresponding value of $Y$ is:

$$
Y^{*}=\frac{\left(c+F^{*}\right)\left(m-s F^{*}\right)}{\beta \rho F^{*} n r} .
$$

The point $\left(Y^{*}, F^{*}\right)$ is an equilibrium point where stocking rate, pasture, and soil nutrient status are in balance. It lies in the physical region when $Y^{*} \geq 0$, which is the only region necessary to consider as the feasible region $(Y, F \geq 0)$ is invariant. This is assured when:

$$
\frac{\left(c+F^{*}\right)\left(m-s F^{*}\right)}{\beta \rho F^{*} n r} \geq 0 .
$$

That is:

$$
n \leq \frac{a m}{r(d s+m)}=n^{*} .
$$

Therefore when $n<n^{*}$ there are two equilibrium points in the physical region. At $n=n^{*}$ the two points coincide (see section 3.2), and when $n>n^{*}$ there is a single equilibrium at $\left(0, \frac{m}{s}\right)$. The next step is to determine for which parameter values the steady state points are stable (attracting) as only stable steady states are observed in physically feasible systems.

Figure 1 shows that in the absence of grazing $(n=0)$ the pasture reaches an equilibrium point at ceiling mass ( $\left.4000 \mathrm{kgDM} \mathrm{ha}{ }^{-1}\right)$. At this point $F$ is at the level $F=\frac{m}{s}$, given that there are no animal related losses. As $n$ increases (at constant $m$ ) the equilibrium $Y$ and $F$ decline to a point where the equilibrium $F$ is at a minimum. The value of $F^{*}$ for a given $m$ is the point at which soil losses $(s F)$ are minimised, therefore this must be the point where animal $\mathrm{P}$ intake (hence $\mathrm{P}$ loss) is maximised. As $n$ increases further the equilibrium value of $F$ increases while the equilibrium value of $Y$ continues to fall. This represents falling animal intake in the face of low pasture mass, with soil related $\mathrm{P}$ loss again increasing. Even at the minimum equilibrium $F$ value, soil related loss comprises about $69 \%$ of total $\mathrm{P}$ loss. Given maximum annual $\mathrm{P}$ uptake of $55 \mathrm{kgP}$ ha $\mathrm{yr}^{-1}$ (and $\beta=0.3$ ) and the high soil $\mathrm{P}$ levels generated by long term rates of $m$ at $40 \mathrm{kgP} \mathrm{ha}^{-1} \mathrm{yr}^{-1}$ these outcomes are consistent with field observations and other models. 


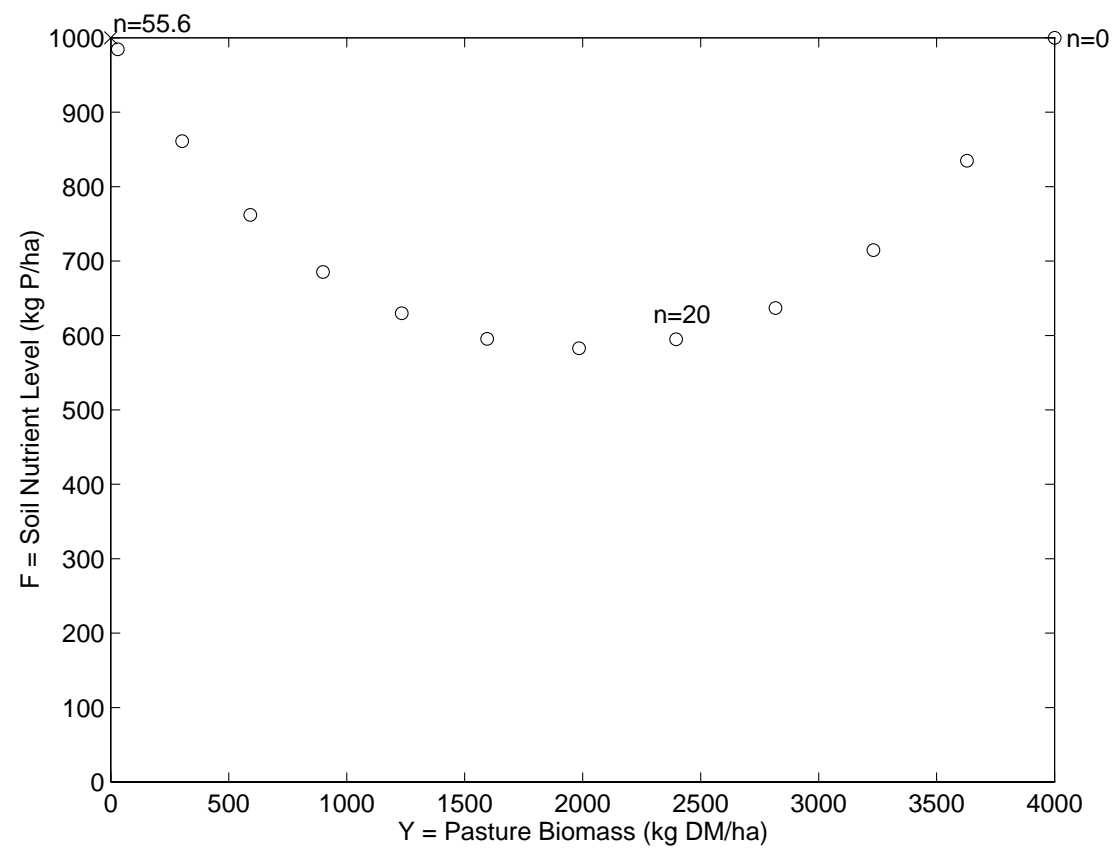

Figure 1. Change in the stable steady state of the system under different stocking rates with an annual fertiliser application of $m=40 \mathrm{kgP} \mathrm{ha}{ }^{-1} \mathrm{yr}^{-1}$.

Stability of $\left(0, \frac{m}{s}\right)$

Identifying the stability of the equilibrium points involves analysis of the Jacobian matrix at the equilibrium point (Edelstein-Keshet 1987, Woodward in press b.). This represents a linear approximation to the system in a neighbourhood of that point. The equilibrium point is locally asymptotically stable if the real parts of all (in this two-dimensional case, both) eigenvalues are strictly negative.

The Jacobian at any point $(Y, F)$ is:

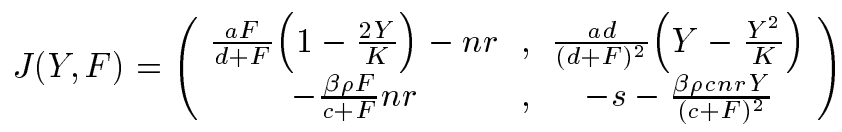

For the equilibrium point $\left(0, \frac{m}{s}\right)$, the eigenvalues are:

$$
\lambda_{1}=\frac{a m}{d s+m}-n r
$$




$$
\text { and } \lambda_{2}=-s \text {. }
$$

So for stability we need the real parts of both eigenvalues to be negative; so

$$
\lambda_{1}<0 .
$$

That is:

$$
n>\frac{a m}{r(d s+m)} \text {. }
$$

It will be shown later that this steady state is locally asymptotically stable if and only if $\left(Y^{*}, F^{*}\right)$ is physically unrealistic.

\section{Stability of $\left(Y^{*}, F^{*}\right)$}

For the equilibrium point $\left(Y^{*}, F^{*}\right)$, the eigenvalues are too complicated to present here, and they may be complex for certain parameter values. However the real parts are always negative when $\left(Y^{*}, F^{*}\right)$ is in the physical region, so that the equilibrium point is always stable. This follows not by finding the eigenvalues of $J\left(Y^{*}, F^{*}\right)$ explicitly but by observing that

$$
\begin{aligned}
J\left(Y^{*}, F^{*}\right) & =\left(\begin{array}{ccc}
-\frac{Y^{*}}{K} \frac{a F^{*}}{d+F^{*}} & \frac{Y^{*} d}{\left(d+F^{*}\right) F^{*}} n r \\
-\frac{\beta \rho F^{*}}{c+F^{*}} n r & ,-s-\frac{\beta \rho c n r Y^{*}}{\left(c+F^{*}\right)^{2}}
\end{array}\right) \\
& =\left(\begin{array}{cc}
w & , x \\
y & , z
\end{array}\right) .
\end{aligned}
$$

Thus the eigenvalues $\lambda_{1}, \lambda_{2}$ will be found by solving thecharacteristic equation $\lambda^{2}+(-w-z) \lambda+(w z-x y)=0$ where $w$ and $z$ are both negative and $(w z-x y)$ is positive. From this we may conclude that the real parts of a solution to this equation are always negative.

Complex eigenvalues produce a local rotational effect around the equilibrium point, so that the solution spirals into or out of the point. However in this system, complex eigenvalues occur only in a small region very near to the critical value for $n$. When realistic parameter values are used the system evolves in a non-oscillatory fashion (Figure 2), consistent with field observations of changes in pasture yield and soil fertility in response to changes in fertiliser application (e.g., Nguyen et. al., 1989 ; Lambert et. al., 1990). In addition, for realistic parameter values the oscillations will be too small to be measurable in the field. For real eigenvalues, the equilibrium point is known as a stable node (see Figure 3).

The final case to consider is where $n=n^{*}=\frac{a m}{r(d s+m)}$; i.e. where the two equilibrium points coincide. It is not then possible to directly determine stability from the 


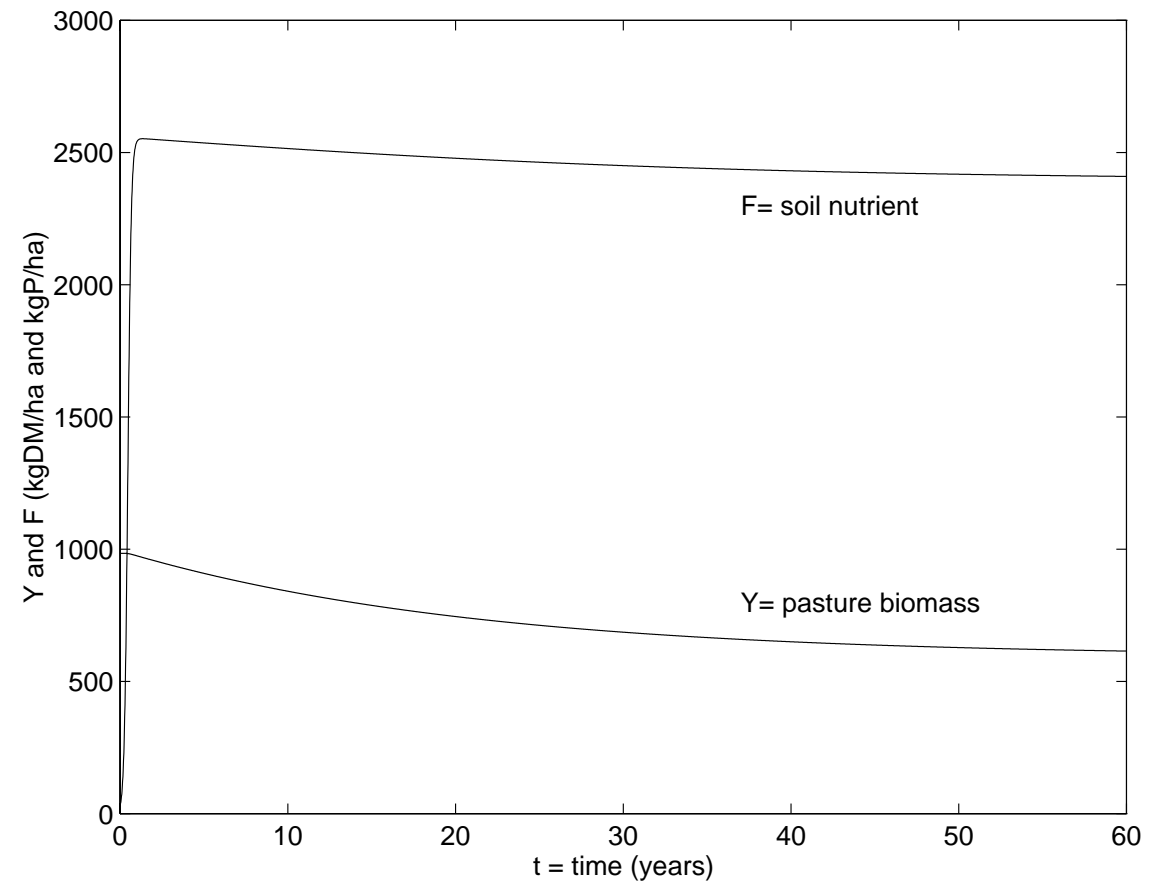

Figure 2. Values of pasture biomass and soil nutrient as time increases for $m=40 \mathrm{kgP} \mathrm{ha}^{-1}$ $\mathrm{yr}^{-1}, n=20$ ewes/ha. Initial state is $Y=50, F=1000$.

Jacobian because one of the eigenvalues is zero. Using a computer to trace paths numerically indicates that the point will be stable in this case.

For small $n$ there are two equilibrium points in the physical region, one of which is stable. As $n$ becomes larger the two equilibrium points become closer and eventually become indistinct (see Figure 4 ). At that value of $n$, the equilibrium point is stable. As $n$ increases further, $\left(Y^{*}, F^{*}\right)$ moves out of the physical region. Due to the direction of evolution along the boundary to the physical region paths can neither cross the $F$ axis at all nor cross the $Y$ axis in the direction of decreasing $F$. In addition the paths are bounded because if $F>\frac{m}{s}$ or $Y>K$ then $\frac{d F}{d t}$ or $\frac{d Y}{d t}$ respectively will be negative. Thus any path that enters or starts in the physical region must stay there.

Thus for a given pasture system and the fixed values for $a, r, d$, and $s$ that accompany it, there is an impassable limit to the amount of stock that can graze on the pasture if complete depletion is to be avoided. Irrespective of the fertiliser 


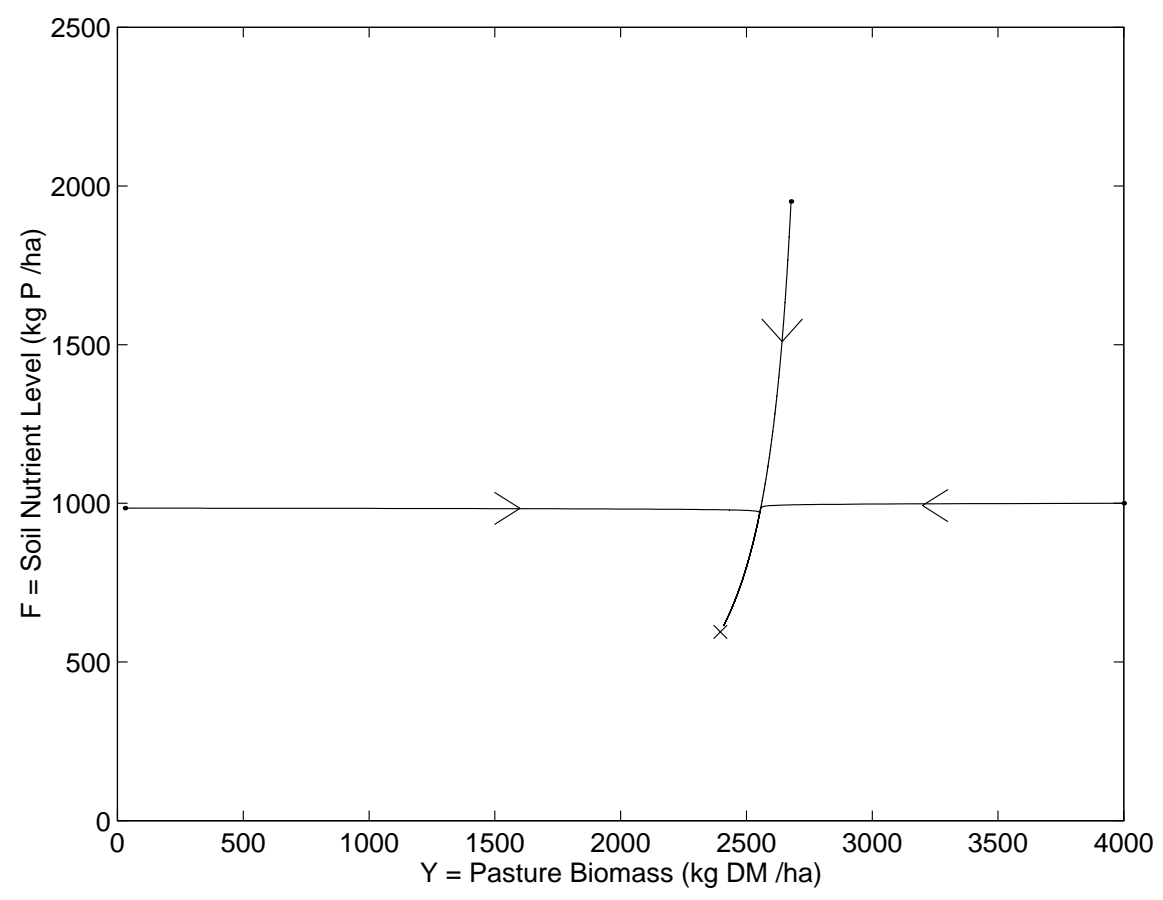

Figure 3. Evolution of the system $\left(m=40 \mathrm{kgP} \mathrm{ha}{ }^{-1} \mathrm{yr}^{-1}, n=20\right.$ ewes/ha) over time, starting from the points marked by $\bullet$ and tending towards the stable point marked by $\times$.

application rate $m$, the largest value of $n^{*}$ is the ratio of $a$, the relative pasture growth rate, to $r$, the relative consumption rate. Any stocking level less than this can be maintained given sufficient fertiliser application and the result will be a stable grazed pasture system with non-zero pasture biomass and hence intake.

\subsection{Thresholds}

The stable point and the system behaviour are determined by the values of the parameters. Changing $n$, the stocking rate, or $m$, the fertiliser application rate, result in the position of the stable point changing. Threshold values of these two control parameters are values where the system behaviour changes qualitatively .

For a given $(m, n)$ pair the steady state $\left(Y^{*}, F^{*}\right)$ yields a certain daily herbage intake level. Of particular interest are the values of $(m, n)$ for which pasture becomes extinct, and hence intake is zero; and secondly, those at which intake is at some minimal survival level (say $\mathcal{I}=0.5 \mathrm{kgDM}$ ewe $^{-1}$ day $^{-1}$.) These thresholds are 


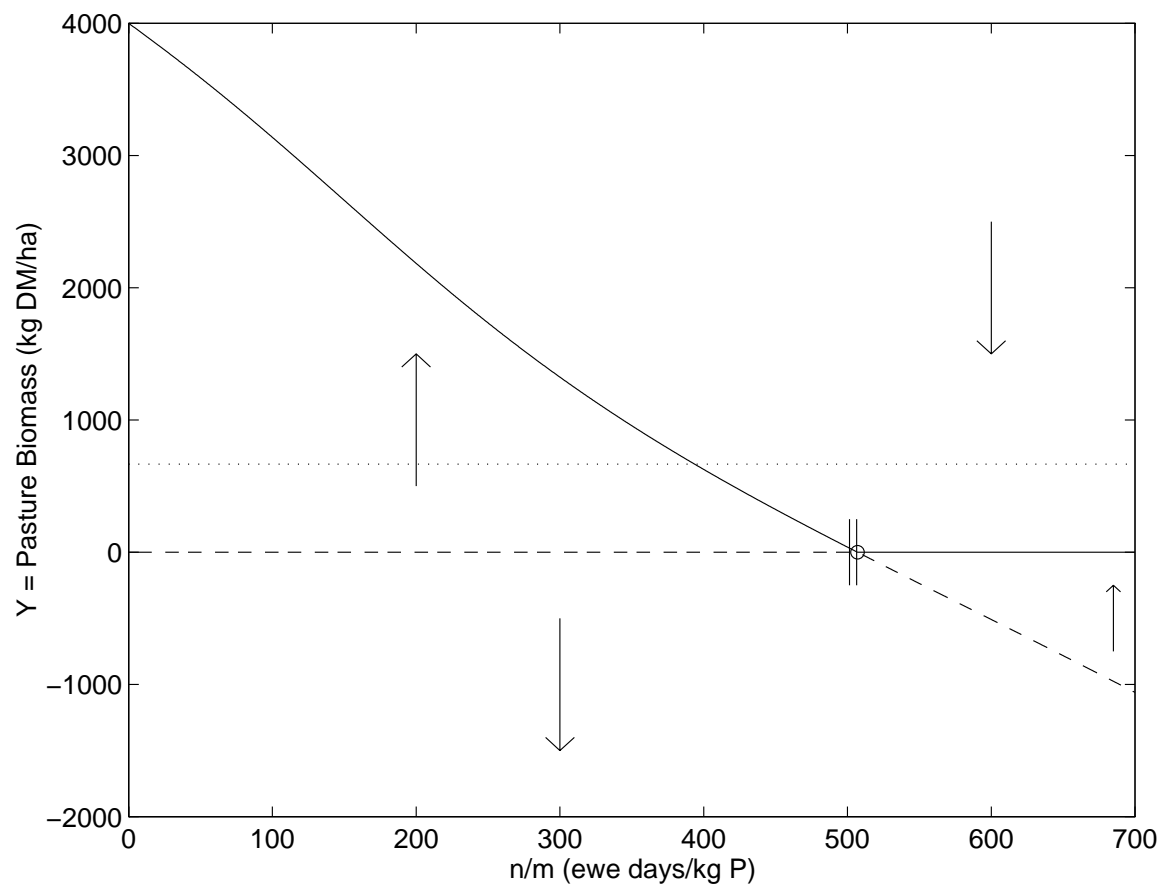

Figure 4. Steady state pasture mass at a range of stocking levels with an annual fertiliser application of $m=40 \mathrm{kgP} / \mathrm{ha} / \mathrm{yr}$. The solid line is stable and the dashed line is unstable. The region between the two vertical lines is the region where the equilibrium points are spirals. The dotted line represents the minimum intake level and the arrows indicate the overall direction of evolution of the system as time increases for non-steady-state initial conditions.

shown in Figure 5 for the parameter values in Table $1 . \mathcal{I}=0$ yields the simple relationship:

$$
n \leq \frac{a m}{r(d s+m)}
$$

which represents the boundary where pasture biomass becomes extinct. Beneath this threshold, equilibrium pasture biomass (and hence intake per animal in $\mathrm{kgDM}$ ewe $^{-1}$ day $^{-1}$ ) is positive and non-zero, whereas above this threshold equilibrium pasture biomass (and hence intake) is zero. The system attains the desirable steady state of non-zero pasture biomass and plant available $\mathrm{P}$ only when the inequality in equation (17) is satisfied. Further it implies that stocking rates of $n=\frac{a}{r}$ or greater can never be sustained on any fertiliser level. 


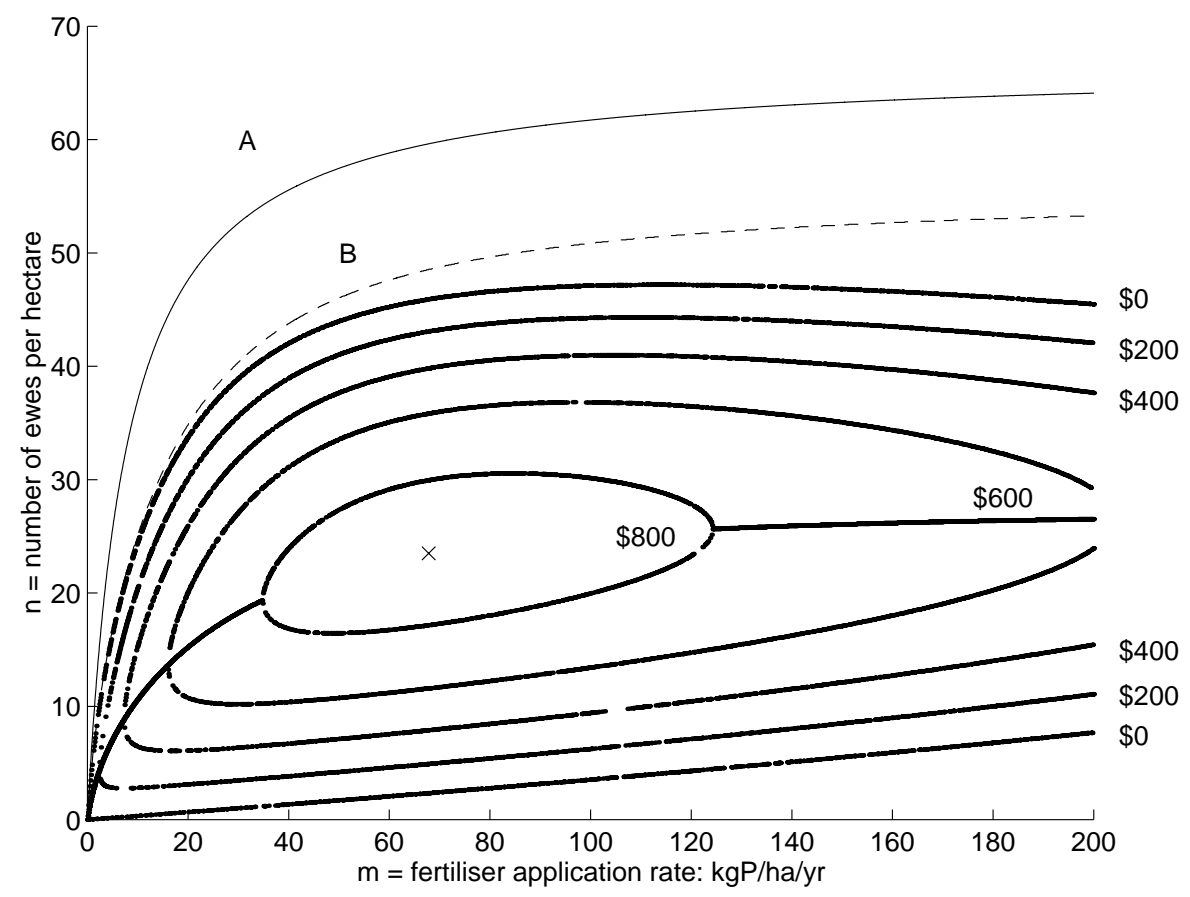

Figure 5. Thresholds region of the $(m, n)$ parameter plane. Three qualitatively distinct regions are shown where A: Pasture extinction due to overstocking, B: Ewes are not eating enough pasture to survive. The region under the dashed line is the economic region. $\times$ indicates the most profitable $(\mathrm{m}, \mathrm{n})$ strategy according to the simple economic model presented in this paper.

The second threshold on figure 5 is a dashed line indicating where $r Y$, the intake per animal, is equal to some minimal survival level, say $\mathcal{I}=0.5 \mathrm{kgDM}$ ewe $\mathrm{day}^{-1}$. This is a survival threshold; above this stocking level it is expected that the animals will not be able to survive.

\subsection{Economic Optimisation}

A simple economic optimisation may be overlaid onto the system dynamics, and this illustrates the use of analytic models in economic analysis. By making some simplifying assumptions about animal production and given estimates of product value and fertiliser cost $(\mathcal{C})$, we can calculate the values of $n$ and $m$ which produce an optimal profit. We assume that income from sheep is derived only when their intake is greater than the intake $(\mathcal{I})$ needed for survival. We further assume that intake above maintenance is linearly related to production of saleable product 
(meat, wool) and from this derive the revenue $(\mathcal{R})$ per $\mathrm{kgDM}$ consumed above $\mathcal{I}$.

From these we can calculate the effect of fertiliser rate and stocking rate on farm income net of fertiliser costs. This assumes no variable costs associated with stocking rate changes. It is assumed that an animal on a survival intake earns nothing, and an animal eating $550 \mathrm{kgDM} \mathrm{yr}^{-1}$ earns $\$ 36.75$. The figure of one stock unit eating $550 \mathrm{kgDM} \mathrm{yr}^{-1}$ is taken from Coop (1965) and the value of $\$ 36.75$ is typical of gross income for stock units on sheep and beef units in the northern North Island of New Zealand (MAF 1996). We interpolate linearly to give the total annual revenue per hectare as

$$
365 n(r Y-\mathcal{I}) \mathcal{R}
$$

where $\mathcal{I}=0.5 \mathrm{kgDM}$ ewe $^{-1}$ day $^{-1}$ is a typical survival intake and $\mathcal{R}=0.10 \$$ $\mathrm{kgDM}^{-1}$ is the ultimate value of the additional food eaten. Subtracting fertiliser costs, annual profit is then

$$
\mathcal{A P}=365(n(r Y-\mathcal{I}) \mathcal{R}-m \mathcal{C}) \quad \$ \mathrm{ha}^{-1} \mathrm{yr}^{-1} .
$$

The parameters and variables are given in Table 2 . With this we can compute profit over the range of $n$ and $m$. It transpires that there is a maximum value for $\mathcal{A P}$ over the $(n, m)$ plane. This point is marked in figure 5 and represents an optimal profit of $\$ 877 \mathrm{ha}^{-1} \mathrm{yr}^{-1}$, achieved when there is a stocking rate of $n=23$ ewes $\mathrm{ha}^{-1}$ and annual fertiliser input of $m=68 \mathrm{kgP} \mathrm{ha} \mathrm{yr}^{-1}$. At this point, steady pasture mass is $Y^{*}=2348 \mathrm{kgDM} \mathrm{ha}^{-1}$ and annual intake per ewe is $642 \mathrm{kgDM}$. These figures are somewhat high, reflecting the constant growth rate parameter, $a=0.05$ day $^{-1}$, which implies a maximum rate of pasture growth of $50 \mathrm{kgDM} \mathrm{ha}^{-1}$ day $^{-1}$ when soil $\mathrm{P}$ is not limiting. The monetary values given for this calculation are typical for New Zealand conditions (with stock units equating to a $50 \mathrm{~kg}$ ewe) in recent years. These are just estimates to illustrate the procedure.

The contours of profit in figure 5 suggest that $\mathcal{A P}$ is less sensitive to changes in fertiliser rate $m$ than to changes in stocking rate $n$ (over much of the parameter range), in line with conventional wisdom (McMeekan 1956). However, the shape of the contours has the potential to be influenced by the relative prices of fertiliser and animal product, so that changes in the prices could change the importance of fertiliser rate compared to stocking rate. We note the even spacing of the stocking contours.

\section{Discussion}

The model presented in this paper has been constructed from component knowledge of biological and ecological interactions. This mathematical representation allows easy analysis of the coupled dynamics of the two state variables with a view to 
Table 2. Variables, parameters and their estimated values and units. Results of optimisation.

\begin{tabular}{|c|c|c|c|}
\hline & Estimate & Units & Description \\
\hline $\begin{array}{l}\mathcal{A P} \\
\mathcal{I} \\
\mathcal{R} \\
\mathcal{C} \\
n \\
r \\
Y \\
m\end{array}$ & $\begin{array}{l}0.5 \\
0.10 \\
3.00\end{array}$ & $\begin{array}{l}\$ \mathrm{ha}^{-1} \text { year }^{-1} \\
\mathrm{kgDM} \mathrm{ewe}^{-1} \mathrm{day}^{-1} \\
\$ \mathrm{kgDM}^{-1} \\
\$ \mathrm{kgP}^{-1} \\
\text { ewes ha-1 } \\
\text { ha ewe } \\
\text { kgDM ha } \mathrm{day}^{-1} \\
\mathrm{kgP} \mathrm{ha}^{-1} \text { day }^{-1}\end{array}$ & $\begin{array}{l}\text { annual profit per hectare } \\
\text { minimum intake for maintenance } \\
\text { revenue per kgDM } \\
\text { cost per kgP } \\
\text { stocking rate } \\
\text { individual consumption coefficient } \\
\text { pasture biomass } \\
\text { fertiliser application rate }\end{array}$ \\
\hline & $\begin{array}{l}\text { Optimised } \\
\text { Values }\end{array}$ & & \\
\hline $\begin{array}{l}\mathcal{A P} \\
Y^{*} \\
n \\
m\end{array}$ & $\begin{array}{l}877 \\
2348 \\
23 \\
0.19 \\
68\end{array}$ & $\begin{array}{l}\$ \mathrm{ha}^{-1} \text { year }^{-1} \\
\mathrm{kgDM}^{-1} \mathrm{ha}^{-1} \\
\text { ewes ha-1 } \\
\mathrm{kgP} \mathrm{ha}^{-1} \text { day }^{-1} \\
\mathrm{kgP} \mathrm{ha}^{-1} \text { year }^{-1}\end{array}$ & \\
\hline
\end{tabular}

conducting steady state analysis and examining the thresholds.

Steady state analysis showed that the system exhibits a single stable steady state where a constant annual fertiliser application may sustain stocking rate, pasture yield and soil nutrient status indefinitely. However, when stocking level exceeds a critical value pasture tends to extinction, so that animal intake falls below biologically reasonable levels. In practice this equilibrium $\left(0, \frac{m}{s}\right)$ is of little interest for two reasons. Firstly, in managed systems animals are either dead or removed before pasture mass collapses to zero. Secondly, unfertilised natural grasslands and longterm field trials show that even with no fertiliser input, a certain level of pasture yield is maintained for very long periods of time ( $>50$ years). This occurs through the slow release of $\mathrm{P}$ from naturally occurring soil minerals, which is not considered in this model.

Analysis of the parameter thresholds showed that increased fertiliser input is needed to maintain higher stock levels at the same level of feeding, and that there is a stocking level which cannot be maintained regardless of the rate of fertiliser input. Mathematical analysis of this simple model has therefore provided insight into the sustainability of a grazing system in extreme conditions and at the same time gives a theoretical basis for stocking rate and fertiliser policies currently used by farmers.

At the optimum stocking rate, varying $\mathrm{P}$ inputs by $10 \mathrm{kgP} \mathrm{ha}^{-1}$ has little impact on net profit, and the loss from over-application is less than the loss from underapplication. This has two practical implications. A risk-averse farmer may tend to over apply fertiliser rather than risk under-application. However, if there is a 
further cost to over-application (e.g., pollution) then this may suggest lower application rates. Coupling this simple model with stochastic or seasonal production models and land use water quality models may produce some useful insights into farmer behaviour and the impacts of management choices.

This model illustrates the use of dynamical systems in exploring agricultural management. Considerable refinements of the model formulation are of course possible, but the simple model here captures the most important features of the interacting dynamics of pasture and fertility. More detailed models of soil-plant-animal systems would be expected to share the same qualitative behaviour as this simple model. This reflects the fact that this simple model reproduces the qualitative behavior observed in the field. More detailed models may however be useful in determining the effect of seasonality, fertiliser timing and release rate, and animal management or optimum management strategies. It is our intention to further develop and apply this model to these issues.

\section{Acknowledgements}

The authors wish to acknowledge the contributions of Tony Pleasants and Dr Doug Edmeades of AgResearch. The support of the Mathematics Department, University of Auckland summer research scholarship to I.D.Wickham during the early part of this work is gratefully acknowledged.

\section{References}

[1] Bircham, J.S. (1981) Herbage growth and utilisation under continuous stocking management. Ph.D. thesis, University of Edinburgh.

[2] Coop, I.E. (1965) A review of the ewe-equivalent system. New Zealand Agricultural Science 1 (3): 13-18.

[3] Cornforth, I.S., and Sinclair, A.G. (1984) Model for calculating maintenance phosphate requirements for grazed pastures. New Zealand Journal of Experimental Agriculture 10: 53-61.

[4] Edelstein-Keshet, L. (1987) Mathematical models in biology. McGraw-Hill, New York.

[5] Lambert, M.G., Devantier, B.P., Nes, P. and Penny, P.E. (1985) Losses of nitrogen, phosphorus and sediment in runoff from hill country under different fertiliser and grazing management regimes. New Zealand Journal of Agricultural Research 28: 371-379. 
[6] Lambert, M.G., Clark, D.A. and Mackay, A.D. (1990) Long term effects of withholding phosphate application on North Island hill country: Ballantrae. Proceedings of the New Zealand Grasslands Association 51: 25-28.

[7] Metherell, A.K., McCall, D.G., and Woodward, S.J.R. (1995) Outlook: a phosphorus fertiliser decision support model for grazed pastures. In Fertiliser requirements of grazed pasture and field crops: Macro and micro-nutrients. (Eds Currie, L.D. and Loganathan, P.) Occasional Report No.8 of the Fertiliser and Lime Research Centre, Massey University, Palmerston North, New Zealand. Massey University. pp24-39.

[8] McMeekan, C.P.(1956) Grazing managament and animal production. Proceedings of the VIIth International Grassland Congress, pp146-156.

[9] MAF (1996) Farm Monitoring Report North Region July 1996. Ministry of Agriculture, Hamilton, New Zealand.

[10] Nguyen, M.L., Rickard, D.S. and McBride, S.D. (1989) Pasture production and changes in phosphorus and sulphur states in irrigated pastures receiving long-term applications of super phosphate fertilizer. New Zealand Journal of Agricultural Research 32: $245-262$.

[11] Nguyen, M.L. and Goh, K.M. (1992) Nutrient cycling and losses based on a mass-balance model in grazed pastures receiving long-term superphosphate applications in New Zealand. 1 Phosphorus. Journal of Agricultural Science, Cambridge 119: 89-106.

[12] Snaydon, R.W. (1981) The ecology of grazed pastures. In Morley, F.H.W. (ed) Grazing Animals. Elsevier. pp13-31.

[13] Woodward, S.J.R. (1996) A dynamic nutrient carryover model for pastoral soils and its application to optimising fertiliser allocation to several blocks with a cost constraint. Review of Marketing and Agricultural Economics 64: 1-11.

[14] Woodward, S.J.R. (in press a) Formulae for predicting animal's daily intake of pasture and grazing time from bite weight and composition. Livestock Production Science.

[15] Woodward, S.J.R (in press b) Dynamical systems models and their application to optimising grazing management. In Peart, R.M. and Curry, R.B. (eds) Agricultural Systems Modelling and Simulation. Marcel-Dekker. 


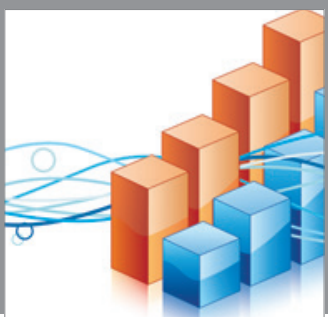

Advances in

Operations Research

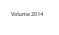

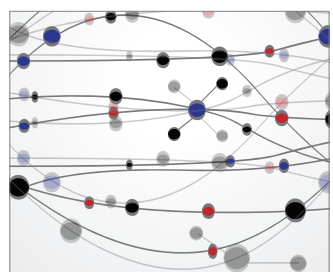

\section{The Scientific} World Journal
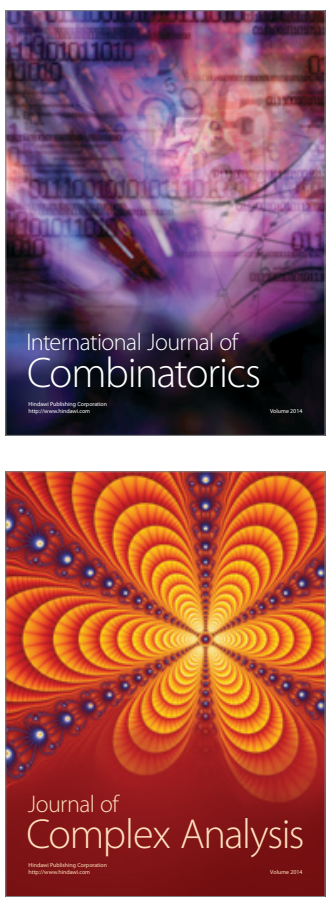

International Journal of

Mathematics and

Mathematical

Sciences
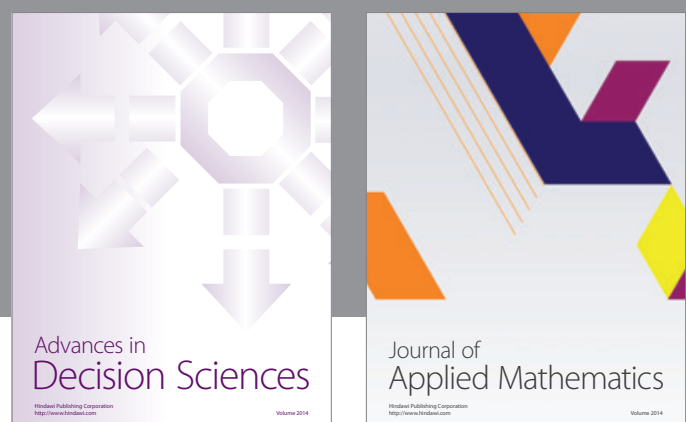

Journal of

Applied Mathematics
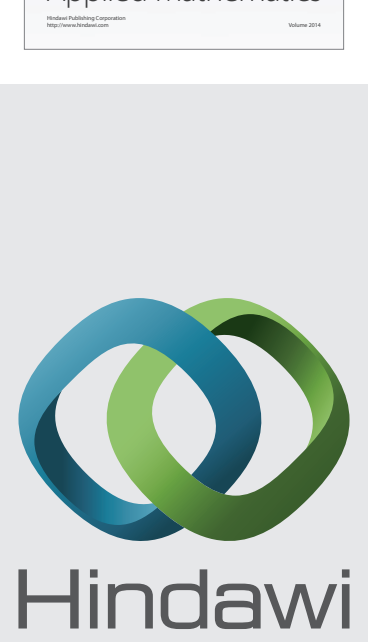

Submit your manuscripts at http://www.hindawi.com
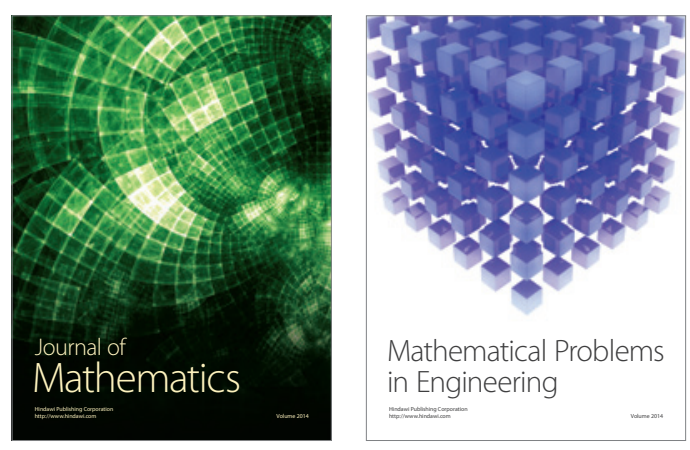

Mathematical Problems in Engineering
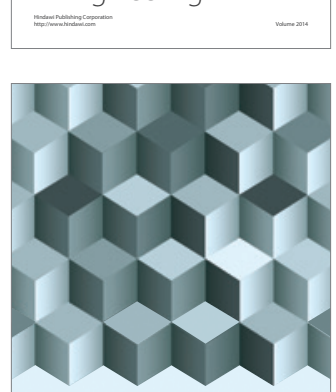

Journal of

Function Spaces
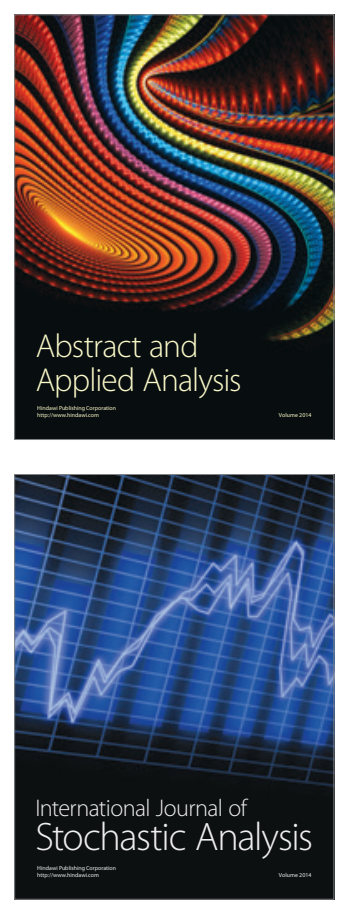

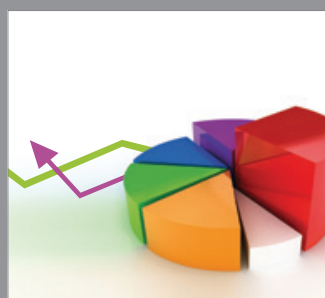

ournal of

Probability and Statistics

Promensencen
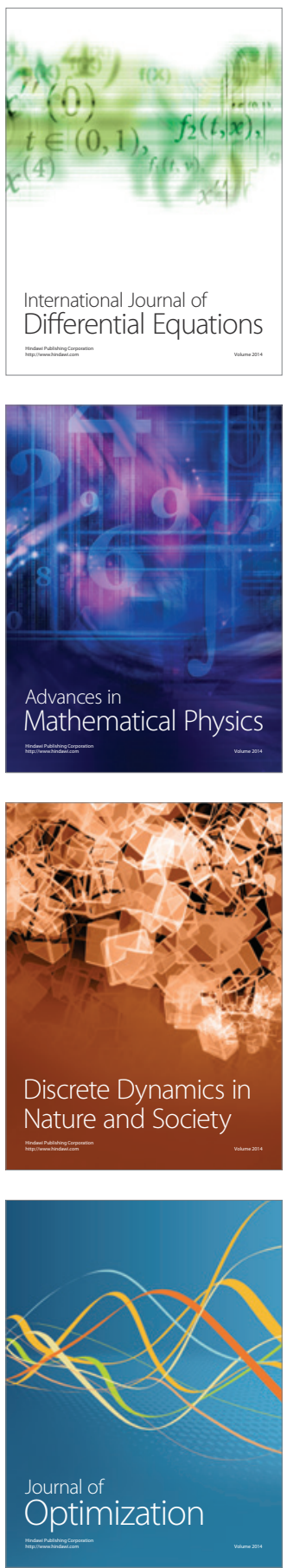